\title{
LETTERS
}

\section{Inequity a root cause of poor health among Indigenous peoples}

In his article, "Reducing the cost of inequality," Dr. Trevor Hancock, an internationally respected leader in public health, brings attention to a substantially under-recognized part of the Canadian health care system: ${ }^{1}$ the health of vulnerable populations. Dr. Hancock focuses specifically on the unfairly unequal treatment of Indigenous people in Canada. As he points out, in a country as wealthy as Canada, this is a continuing and persisting inequality.

I would challenge, however, that this goes further than an inequality that simple economics can fix: rather, it is inequity. It should be more than simple resource allocation; it should be social justice and fairness, which are arguably true Canadian values, and to which Dr. Hancock does allude. As an Indigenous physician, I have seen first hand the devastating effects of poor health on Indigenous people, stemming directly from colonization, residential schools, racism and stereotypes, which keep us all from obtaining health equity. As the Truth and Reconciliation Commission concluded, what is really needed is a paradigm shift; the "us versus them" attitude among Canadians must change. ${ }^{2}$

There is no better place to start than with health care. The tragic case of Brian Sinclair, an Indigenous man who died in the waiting room of a Winnipeg emergency department, should have been a clear wake-up call that achieving equality in itself will not be sufficient. A real shift in the "hearts" of Canadians must occur, and as Call to Action number 22 from the Truth and Reconciliation Commission states, "We call upon those who can effect change within the Canadian health care system to recognize the value of Aboriginal healing processes."2

Indeed, Dr. Geoffrey Rose, a renowned epidemiologist, published a seminal paper in 1985, which describes how those at high risk of illness are those at any risk of illness, not just high risk, simply because there are more of them. ${ }^{3}$ Thus, combining the individual and population health approaches will lead to improvement in the health of those who are vulnerable, as well as those at any level of risk. This is at the very "heart" of public health.

\section{Daniel W. McKennitt MD MPH}

Family physician, School of Public Health, University of Alberta, Edmonton, Alta.

Cite as: CMAJ 2018 July 3;190:E807. doi: 10.1503/cmaj.69405

\section{References}

1. Hancock T. Reducing the cost of inequality. CMAJ 2018;190:E92

2. Honouring the truth, reconciling for the future: summary of the final report of the Truth and Reconciliation Commission of Canada. Winnipeg: Truth and Reconciliation Commission of Canada; 2015.

3. Rose G. Sick individuals and sick populations. Int J Epidemiol 1985;14:32-8.

Competing interests: None declared. 